\title{
REMISSION RATE OF PRE-B ALL (ACUTE LYMPHOBLASTIC LEUKEMIA) AFTER INDUCTION CHEMOTHERAPY FOLLOWING UNITED KINGDOM ACUTE LYMPHOBLASTIC LEUKAEMIA 2011 (UKALL 2011) TRIAL PROTOCOL
}

\author{
Hafiz Muhammad Murtaza, Tariq Ghafoor*, Muhammad Shaheen Iqbal** \\ Pak Emirates Military Hospital/National University of Medical Sciences (NUMS) Rawalpindi Pakistan, *Armed Forces Bone Marrow Transplantation/National \\ University of Medical Sciences (NUMS) Rawalpindi Pakistan, ${ }^{* * P a k i s t a n ~ C o u n c i l ~ o f ~ S c i e n t i f i c ~ a n d ~ I n d u s t r i a l ~ R e s e a r c h, ~ I s l a m a b a d ~ P a k i s t a n ~}$
}

\section{ABSTRACT}

Objective: To find out the rate of remission of Pre-B Acute Lymphoblastic Leukaemia in children at the end of induction treatment with United Kingdom Acute Lymphoblastic Leukaemia (UKALL) 2011 chemotherapy protocol.

Study Design: Prospective observational study.

Place and Duration of Study: Paediatric Oncology Unit, Combined Military Hospital Rawalpindi, from Nov 2017 to Oct 2018. Methodology: Data of newly diagnosed patients of Pre-B Acute lymphoblastic Leukaemia, between 1 and 15 years of age was analysed. Patients were divided into low and high-risk groups and treated with United Kingdom Acute Lymphoblastic Leukaemia 2011 induction chemotherapy on regimens A and B respectively. Bone marrow aspiration was performed at the end of induction therapy (28 days), to document their remission status. Patients having $\leq 5 \%$ of blast cells were categorized to be in remission state and those with $>5 \%$ blast cells were not considered in a state of remission.

Results: A total of 79 patients, $45(57 \%)$ male and $34(43 \%)$ females were enrolled. The mean age was $5.79 \pm 3.59$ years. Fever $(86.1 \%)$ and pallor $(77.2 \%)$ were the most common presentations. Fifty-three $(67.1 \%)$ patients were treated with regimen A and $26(32.9 \%)$ had regimen B chemotherapy. Febrile neutropenia and myopathy were the most common complications seen in 73 $(92.4 \%)$ and $54(71.1 \%)$ patients respectively. Eight patients $(10.1 \%)$ died during induction chemotherapy. Bone marrow aspiration done at the end showed a $100 \%$ rate of remission for both regimens $\mathrm{A}$ and $\mathrm{B}$.

Conclusion: Risk-based treatment of paediatric Acute lymphoblastic Leukaemia achieves very good remission after induction treatment. Treatment-related mortality is high in our setup.

Keywords: Acute lymphoblastic Leukaemia, Induction chemotherapy, Pre-B acute lymphoblastic leukaemia, Remission rate, United Kingdom acute lymphoblastic leukaemia.

\footnotetext{
This is an Open Access article distributed under the terms of the Creative Commons Attribution License (http://creativecommons.org/licenses/by/4.0), which permits unrestricted use, distribution, and reproduction in any medium, provided the original work is properly cited.
}

\section{INTRODUCTION}

Acute lymphoblastic leukaemia (ALL) is known as the most prevalent malignancy in paediatric age group and it accounts for $80 \%$ cases of acute leukaemia and its subtype Pre-B ALL is considered the most prevalent subtype ${ }^{1-3}$. In Paediatric Precursor-B Acute Lymphoblastic Leukaemia (Pre-B-ALL), an early response to chemotherapy regimens after induction has a high prognostic significance which predicts the future outcome of patients ${ }^{4,5}$. Chemotherapy intensification regimens have shown a remarkable improvement in the cure rate of pediatric patients from ALL ${ }^{6}$. The response of disease to treatment is affected by the drug sensitivity of blast cells as well as pharmacogenomics and pharmacodynamics values of the host, however, an early response to the treatment has high prognostic significance. The rate at which cells of leukaemia are eradicated after the commencement of disease treatment and the status of residual disease after induction is helpful in determining the future outcome of pati-

Correspondence: Dr Hafiz Muhammad Murtaza, Department of Paediatric Oncology, PEMH Rawalpindi Pakistan

Received: 12 Jun 2019; revised received: 01 Dec 2019; accepted: 05 Dec 2019 ents and treatment can be modified to achieve long term control of the disease ${ }^{7,8}$. Morphology of the bone marrow at the end of induction treatment is used to evaluate response to chemotherapy treatment ${ }^{9}$. There are a number of studies conducted previously in our setup, this study was intended to extend past research in our setup with limited resources with fresh data of patients. It was planned to document the status of remission after the administration of induction chemotherapy in young children suffering from Pre-B ALL in Combined Military Hospital (CMH) Rawalpindi. The purpose of the study was to analyse the rate of remission after induction chemotherapy in pediatric ALL cases.

\section{METHODOLOGY}

This prospective observational studywas performed in the pediatric oncology unit of CMH Rawalpindi, from November 2017 to October 2018. All newly diagnosed cases of Paediatric Precursor-B Acute Lymphoblastic Leukaemia (Pre-B-ALL) between 1-15 years of age were included. Patients who had received chemotherapy at any other center before coming to $\mathrm{CMH}$ and T-cell acute Lymphoblastic Leukaemia and lym- 
phoma were excluded. Informed consent of patients was taken and study was started after approval from Hospital Ethics Review Committee.

Acute Lymphoblastic leukaemia (ALL) was diagnosed by applying standard techniques of bone marrow morphology and immunophenotyping. Bone marrow aspiration sampling was done through the posterior superior iliac spine with a bone marrow biopsy needle under sedation after the informed consent of parents/guardians of patients. Cerebrospinal fluid (CSF) analysis was done to document CNS involvement. Baseline investigations including full blood count, biochemical profile (liver and renal function tests, lactate dehydrogenase, uricacid, calcium, phosphate levels) and echocardiography were performed before starting chemotherapy.

Patients were divided into two risk and treatment groups as per National Cancer Institute (NCI) criteria. Patients having WBC count less than 50,000 cells $/ \mathrm{mm}^{3}$ $\left(50.0 \times 10^{9}\right.$ cells/L) and age more than one year and $<10$ years were categorized in standard-risk group and patients having WBC count $>50,000$ cells $/ \mathrm{mm}^{3}(50 \mathrm{x}$ $10^{9}$ cells/L) or age $>10$ years or unfavorable cytogenetics were placed in high-risk group. Induction chemotherapy was given as per UKALL 2011 standard Arm protocols. The standard risk group of patients received regimens A chemotherapy consisting of Dexamethasone, Vincristine, and Peg-Asparaginase and High-risk group of patients received regimen $B$ consisting of methotrexate chemotherapy according to the age of the patient.

Neutropenic fever was managed with broadspectrum antibiotics and antifungal as per the Infectious Disease Society of America (IDSA) guidelines. Blood products were transfused on as and when required basis. Bone marrow aspiration was performed after the induction phase of chemotherapy to document the remission status of patients. Patients having $\leq 5 \%$ of blast cells were categorized in remission while patients with $>5 \%$ blast cells were labelled as not in remission.

Independent sample t-test and chi-squared tests were used for comparison between continuous and categorical variables. All statistical analyses were performed using SPSS-23 and a $p$-value of $\leq 0.05$ was considered statistically significant.

\section{RESULTS}

During the study period of one year, data of 79 patients of pre-B ALL including $45(57.0 \%)$ boys and $34(43 \%)$ girls 'data were analyzed. The mean age was $5.79 \pm 3.59$ years. The main presenting features were fever, pallor, bruising and body aches. The mean time to report to an oncologist after the onset of symptoms was $61.59 \pm 62.02$ days. Fifty-three $(67.1 \%)$ patients were kept in the standard-risk group and were treated with regimen A chemotherapy and 26 (32.9\%) patients were in a high-risk group and they were given regimen B chemotherapy (table-I).

Table-I: Patients' age, gender, blood counts and presentations with respect to regimens and their $p$-value.

\begin{tabular}{|c|c|c|c|c|}
\hline Variable & $\begin{array}{c}\text { Regimen A } \\
\text { n (\%) }\end{array}$ & $\begin{array}{c}\text { Regimen B } \\
\text { n ( } \%)\end{array}$ & $\begin{array}{l}\text { Total } \\
\text { n }(\%)\end{array}$ & $p$-value \\
\hline Total number & $53(67.1 \%)$ & $26(32.9 \%)$ & $79(100 \%)$ & \\
\hline Age (Years) & $4.68 \pm 2.79$ & $8.06 \pm 4.00$ & $5.79 \pm 3.59$ & \\
\hline \multicolumn{5}{|l|}{ Gender } \\
\hline Male & $29(54.7)$ & $16(61.5)$ & $45(57.0)$ & \\
\hline Female & $24(45.3)$ & $10(38.5)$ & $34(43.0)$ & \\
\hline \multicolumn{5}{|c|}{ Blood Counts at the Time of Presentation } \\
\hline WBC count $\left(x 10^{9} / \mathrm{L}\right)$ & $14.26 \pm 14.16$ & $68.74 \pm 71.43$ & $32.19 \pm 49.32$ & 0.001 \\
\hline Haemoglobin $(\mathrm{g} / \mathrm{dl})$ & $7.58 \pm 2.63$ & $7.80 \pm 2.64$ & $7.65 \pm 2.62$ & 0.882 \\
\hline Platelets (x109/L) & $77.28 \pm 107.72$ & $49.96 \pm 39.02$ & $68.29 \pm 91.60$ & 0.012 \\
\hline Time to report to oncologist & $66.30 \pm 63.84$ & $52.00 \pm 58.17$ & $61.59 \pm 62.02$ & 0.544 \\
\hline \multicolumn{5}{|l|}{ Presentation } \\
\hline Fever & $46(86.8)$ & $22(84.6)$ & $68(86.1)$ & 0.793 \\
\hline Pallor & $44(83.0)$ & $17(65.4)$ & $61(77.2)$ & 0.079 \\
\hline Bruising \& Bleeding & $8(15.1)$ & $6(23.1)$ & $14(17.7)$ & 0.383 \\
\hline Bone Pains & $22(41.5)$ & $14(53.8)$ & $36(45.6)$ & 0.301 \\
\hline Lymphadenopathy & $22(41.5)$ & $12(46.2)$ & $34(43.0)$ & 0.695 \\
\hline CNS Positive & $3(5.7)$ & - & $3(3.8)$ & 0.216 \\
\hline
\end{tabular}

Dexamethasone, Vincristine, Peg-Asparaginase, and Daunorubicin. Both groups also received intrathecal
Neutropenic fever was the commonest side effects seen during induction chemotherapy, in 73 (92.4\%) 
cases. Forty-nine $(92.5 \%)$ patients in regimen A and 24 $(92.3 \%)$ patients in regimen B suffered from neutropenic fever $(p=0.982)$. Steroids induced proximal myopathy was the second most common complication seen in $58(73.4 \%)$ cases. Vincristine-induced neuropathy was documented in $6(8.2 \%)$ cases.

Treatment-related mortality (TRM) was $8(10.1 \%)$. TRM was $4(7.5 \%)$ in regimen A and $4(15.4 \%)$ in the regimen B group $(p=0.278)$. The remaining $71(85.5 \%)$ patients had bone marrow aspiration to document the remission status. Cytogenetics analysis revealed 5 cases of hyperdiploidy and one case was $t(12 ; 21)$, all the results were shown in table-II. The remission was $48 / 48(100 \%)$ in regimen $\mathrm{A}$ and $23 / 23(100 \%)$ in the regimen $\mathrm{B}$ group as shown in table-III.

Table-II: Cytogenetic analysis of samples.

\begin{tabular}{|c|c|c|c|}
\hline \multicolumn{2}{|l|}{ Cytogenetic Analysis } & \multicolumn{2}{|c|}{ n (\%) } \\
\hline \multicolumn{2}{|l|}{ Normal cytogenetics } & \multicolumn{2}{|c|}{$18(70 \%)$} \\
\hline \multicolumn{2}{|l|}{ Hyperdiploidy } & \multicolumn{2}{|c|}{$5(21 \%)$} \\
\hline \multicolumn{2}{|l|}{$\mathrm{t}(12 ; 21)$} & \multicolumn{2}{|c|}{$1(4 \%)$} \\
\hline \multicolumn{4}{|c|}{ Table-III: Rate of remission and TRM of patients. } \\
\hline & Regimen A & Regimen B & Total \\
\hline $\begin{array}{l}\text { Treatment Related } \\
\text { Mortality (TRM) }\end{array}$ & $04(7.5 \%)$ & $04(15.4 \%)$ & 08 \\
\hline Remission Rate & $\begin{array}{l}48 / 48 \\
(100 \%)\end{array}$ & $\begin{array}{c}23 / 23 \\
(100 \%)\end{array}$ & $\begin{array}{c}71 / 71 \\
(100 \%)\end{array}$ \\
\hline
\end{tabular}

\section{DISCUSSION}

The induction phase of chemotherapy aims to eradicate the leukemic cells (lymphoblasts) from the bone marrow. This phase consists of four weeks of chemotherapy. Serial monitoring of disease gives a remarkable insight into the efficacy of the ongoing treatment regimen. After completing 28 days of initial induction chemotherapy all patients undergo bone marrow aspiration cytology. Remission is assessed after induction chemotherapy and it is reflected bythe percentage of blast cells present inbone marrow if it is $<5 \%$, the patient is said to be in remission state ${ }^{10}$. According to a study those patients who are unable to get complete remission within the period of first four weeks of induction chemotherapy, approximately one-half of them undergo a toxic death during the treatmentof induction phase (which is usually caused by infection) and the rest half of these will be labelled as resistant disease (persistent morphologic leukaemia) ${ }^{11-13}$. In our study, some cytogenetic studies were not conclusive due to culture failure. Cytogenetic analysis results were productive in $24(31 \%)$ cases. The majority of cases 18/24 (75\%) had normal cytogenetics. While 5
(21\%) cases showed hyperdiploidy followed by one $(4 \%)$ case of $t(12 ; 21)$ (table-II).

By assessing remission status at the end of induction a physician can predict outcome and can decide to modify treatment regimen. Most patients experiencing persistent leukaemia after completing four-week induction therapy show a poor prognosis and are labelled as chemo-resistant. They may get benefit from hematopoietic stem cell transplant therapy once complete remission from disease is achieved ${ }^{14-16}$. According to a study conducted by Outdo et al, $90 \%$ of patients with ALL can be placed in remission state if treated carefully. This rate has greatly improved since the induction of chemotherapy, previously it was $10 \%{ }^{16}$. Keeping in viewa few certain factors such as lack of resources, and awareness about cancer and its cure, limited studies are available to document the remission status of ALL patients in developing countries. The remission rate of our patients $(100 \%)$ is comparable to other studies conducted in developed countries demonstrating post-induction remission rate upto $95 \% 11-13,17$. Michael et al found that day-29 minimal residual disease (MRD) appeared to predict both early and late relapse and it was the most important prognostic factor ${ }^{7}$.

During our study 8 patients expired atthe induction phase of therapy which demonstrated $10.1 \%$ (8/ 79) treatment-related mortality (TRM). Major causes of mortality were sepsis and febrile neutropenia (90\%). Other causes include respiratory failure and GIT complications and one patient died of brain abscess.

A study which was conducted in Shaukat Khanum Memorial Cancer Hospital and Research Centre, Lahore, Pakistan enrolled 81 patients of ALL with age group of 2-16 years documented $25.9 \%(21 / 81)$ overall induction related mortality with $23 \%(19 / 81)$ mortality among pre-B ALL cases following UKALL 2003 protocol, among them $95 \%(20 / 21)$ cases of mortality were due to infection. It showed $54 \%(44 / 81)$ remission rate on day 8 bone marrow while 45 patients assessed at day 28 showed $100 \%$ remission ${ }^{18}$. Another study conducted in the same institute in Lahore, Pakistan by Asim et al from 2001-2005 documented 12.8\% (39/304) mortality in ALL patients during the induction phase of therapy. It showed $85 \%$ infection-related mortality out of total deaths ${ }^{19}$. The statistics mentioned in these studies closely coincide with our results regarding the achievement of remission induction and minimizing treatment-related mortality. However, the rate of mortality was greater in a study conducted by Maaz et al and it was due to an outbreak of Acinetobacter in 
the hospital. This outbreak had a significant effect on remission status ${ }^{18}$.

Various studies have documented the strong association between minimal residual disease (MRD) levels and the outcome of treatment in childhood ALL 20,21. Dario Campana and Ching-Hon Put in a study supported the concept that assessment of MRD after primary phases of chemotherapy provides a reliable measurement of the sensitivity of the drug in leukemic lymphoblasts 22 .

\section{CONCLUSION}

Risk-based treatment of paediatric ALLwas found to achieves good remission rates after induction treatment. Treatment-related mortality was comparable to other studies. Assessment of the remission status of leukaemia patients at the end of induction has high prognostic sinificant. More multi-centered studies are required to compare the optimum outcome of commonly used chemotherapy regimens in the region.

\section{ACKNOWLEDGMENT}

We are grateful to the paramedical and administrative staff of paediatric oncology department, $\mathrm{CMH}$ Rawalpindi, Pakistan for their dedication and cooperation in the study.

\section{CONFLICT OF INTEREST}

This study has no conflict of interest to be declared by any author.

\section{REFERENCES}

1. Bray F, Ferlay J, Soerjomataram I, Siegel RL, Torre LA, Jemal A. Global cancer statistics 2018: GLOBOCAN estimates of incidence and mortality worldwide for 36 cancers in 185 countries. CA: Cancer J Clin 2018; 68(6): 394-424.

2. Terwilliger T, Abdul-Hay M. Acute lymphoblastic leukemia: a comprehensive review and 2017 update. Blood Cancer J 2017; 7(6): e577.

3. Steliarova-Foucher E, Colombet M, Ries LA, Moreno F, Dolya A. International incidence of childhood cancer, 2001-10: a population-based registry study. Lancet Oncol 2017; 18(6): 719-31.

4. Pui CH, Yang JJ, Hunger SP, Pieters R, Schrappe M, Biondi A, et al. Childhood acute lymphoblastic leukemia: progress through collaboration. J Clin Oncol 2015; 33(27): 2938.

5. Felice MS, Zubizarreta PA, Alfaro EM, Sackmann-Muriel F. Childhood acute lymphoblastic leukemia: prognostic value of initial peripheral blast count in good responders to prednisone. J Pediatr Hematol/Oncol 2001; 23(7): 411-15.

6. Alvarnas JC, Brown PA, Aoun P, Ballen KK, Barta SK, Borate U, et al. Acute lymphoblastic leukemia, version 2.2015. J Natl Compr Cancer Netw 2015; 13(10): 1240-79.
7. Borowitz MJ, Devidas M, Hunger SP, Bowman WP, Carroll AJ, Carroll WL, et al. Clinical significance of minimal residual disease in childhood acute lymphoblastic leukemia and its relationship to other prognostic factors: a Children's Oncology Group study. Blood 2008; 111(12): 5477-85.

8. Relling MV, Dervieux T. Pharmacogenetics and cancer therapy. Nat Rev Cancer 2001; 1(2): 99.

9. O'Connor D, Moorman AV, Wade R, Hancock J, Tan RM, Bartram J, et al. Use of minimal residual disease assessment to redefine induction failure in pediatric acute lymphoblastic leukemia. J Clin Oncol 2017; 35(6): 1-5.

10. Estey E, Faderl S, Kantarjian H. Acute leukemias. Berlin, Heidelberg: Springer Berlin Heidelberg; 2008.

11. Prucker C, Attarbaschi A, Peters C, Dworzak MN, Pötschger U, Urban $C$, et al. Induction death and treatment-related mortality in first remission of children with acute lymphoblastic leukemia: a population-based analysis of the Austrian Berlin-FrankfurtMünster study group. Leukemia 2009; 23(7): 1264.

12. Larsen EC, Devidas M, Chen S, Salzer WL, Raetz EA, Loh ML, et al. Dexamethasone and high-dose methotrexate improve outcome for children and young adults with high-risk B-acute lymphoblastic leukemia: a report from Children's Oncology Group Study AALL0232. J Clin Oncol 2016; 34(20): 2380.

13. Moghrabi A, Levy DE, Asselin B, Barr R, Clavell L, Hurwitz C, et al. Results of the dana-farber cancer institute all consortium protocol 95-01 for children with acute lymphoblastic leukemia. Blood 2007; 109(3): 896-904.

14. Balduzzi A, Valsecchi MG, Uderzo C, De Lorenzo P, Klingebiel T. Chemotherapy versus allogeneic transplantation for veryhigh-risk childhood acute lymphoblastic leukaemia in first complete remission: comparison by genetic randomisation in an international prospective study. Lancet 2005; 366(9486): 635-42.

15. Cooper SL, Brown PA. Treatment of pediatric acute lymphoblastic leukemia. Pediatric Clinics 2015; 62(1): 61-73.

16. Oudot C, Auclerc MF, Levy V, Porcher R, Piguet C, Perel Y, et al. Prognostic factors for leukemic induction failure in children with acute lymphoblastic leukemia and outcome after salvage therapy: the FRALLE 93 study. J Clin Oncol 2008; 26(9): 1496-503.

17. Hunger SP, Mullighan CG. Acute lymphoblastic leukemia in children. Longo DL, editor. N Engl J Med 2015; 373(16): 1541-52.

18. Maaz AU, Badar F, Mahmood T, Al Nassir I. High infection related mortality in Pakistani children with acute lymphoblastic leukaemia during remission induction chemotherapy: a review of data from a single institution. J Cancer Allied Spec 2016; 2(4): 1-5.

19. Asim M, Zaidi A, Ghafoor T, Qureshi Y. Death analysis of childhood acute lymphoblastic leukaemia; experience at Shaukat Khanum Memorial Cancer Hospital and Research Centre, Pakistan. J Pak Med Assoc 2011; 61(7): 666.

20. van Dongen JJ, van der Velden VH, Bruggemann M, Orfao A. Minimal residual diseasediagnostics in acute lymphoblastic leukemia: need for sensitive, fast, and standardized technologies. Blood 2015; 125(26): 3996-4009.

21. Campana D. Minimal residual disease monitoring in childhood acute lymphoblastic leukemia. Curr Opin Hematol 2012; 19(4): 313-18.

22. Campana D, Pui CH. Minimal residual disease-guided therapy in childhood acute lymphoblastic leukemia. Blood 2017; 129(14): 1913-18. 